\title{
Passing the baton: a new chief editor for social psychiatry and psychiatric epidemiology
}

\author{
Heinz Häfner · Paul Bebbington · Craig Morgan
}

Published online: 21 December 2012

(C) Springer-Verlag Berlin Heidelberg 2012

Science is a quintessential human social activity, based as it is on the mutual criticism of collaborating agents. Communication lies at its heart, and advances in communication have always resulted in surges in scientific knowledge. The establishment of networks of scholars allowed the rapid transmission of information—only a few months lay between Lippershey's invention of the telescope in the Netherlands, and Galileo's presentation of a much improved version to the Doge in Venice in 1609. The formalisation of these networks as learned societies dates from the seventeenth century. The printed book drove the scientific developments of the Renaissance, and scholars have always relied on correspondence with colleagues to check out their ideas (Darwin surely would not have been able to write the Origin of Species without his wide supporting circle of correspondents).

Finally the explosion of scientific activity in the nineteenth century occurred in the context of the incremental development of regularly published scientific journals. Over time, this led to the adoption and refinement of the principle of peer review, which, along with the journal

\section{H. Häfner}

Central Institute of Mental Health, PO Box 1221 20,

68072 Mannheim, Germany

P. Bebbington

Mental Health Sciences Unit, Faculty of Brain Sciences,

UCL, 67-73 Riding House St, London W1W 7EJ, UK

\section{Morgan $(\bowtie)$}

Health Service and Population Research,

David Goldberg Centre, Institute of Psychiatry, KCL,

Box P063, De Crespigny Park, London SE5 8AF, UK

e-mail: Craig.morgan@kcl.ac.uk correspondence column, represents a deliberate attempt to encapsulate the mutual-critical essence of scientific activity.

Thus publication in scientific journals has become the imprimatur of science. It is also the redoubt of scientific probity and represents an enormous endeavour of public service. Although they may sometimes grumble, scholars generally regard reviewing the work of colleagues as an entrusted duty, which they do willingly and without payment. However, because the system is one of the glories of science, there are always those who would seek to pervert it, for reasons either of personal academic ambition or of financial cupidity. Such perversions include research fraud, plagiarism, double publication, and the suppression of negative findings. In this regard too, the journal system is an important part of the self-correcting mechanism of science.

It is clear therefore that the editorship of a scientific journal is not a mere administrative function of the publication industry, but a major public trust. The post comes with considerable responsibility and power, which must be deployed for good purposes. The responsibility is twofold, first to science in general, and second to the specific discipline served by the journal. SPPE is fortunate in acquiring the services and commitment of a new chief editor, Dr Craig Morgan.

\section{The early days of social psychiatry and psychiatric epidemiology}

Starting a new Journal always reflects a belief that there is a gap in the market. In the decade before the mid-60s, the custodial system of mental health care practised in large public mental hospitals was undergoing a transition to a 
diverse network of community-based mental health services. As a result, there was an increased appreciation of the impact that the social and community context had on the progression of mental illness and on the progress of patients' lives. Interdisciplinary research into social influences on psychiatric disorder based on a methodology of increasing sophistication was being mounted. It was felt that there should be a journal dedicated to this area of investigation to promote international communication and scientific standards in the field of social psychiatry and psychiatric epidemiology. The journal was launched under its original title of Social Psychiatry, the first issue appearing on 1st August 1966. It asserted that 'A worldwide movement towards a social orientation' (P. 1, Issue 1, Vol. 1) was under way. As it turned out, the initial title of the journal caused a problem in the United States, where in some quarters the term social psychiatry was thought to describe, not a topic of empirical study, but a semi-political movement regarded there as tendentious. In order to emphasise its scientific intent and credentials, the title was expanded to its current form in 1988.

The journal was the initiative of Professor Heinz Häfner. His attempts in 1964 to enlist Springer-Verlag (Heidelberg) as publishers were unsuccessful until he involved an international group of collaborators, from Europe, but also from the USA (Erich Lindemann from Harvard, and Fritz Redlich from Yale). The journal was trilingual (English, German, French): while articles were written in one of these languages, abstracts were provided in all three. However, the increasing hegemony of English as the language of science finally ended this arrangement in 1989.

The journal was the responsibility of three languagebased managing editors, initially John Wing from the Institute of Psychiatry in London, Christian Müller from Lausanne, and Häfner himself, who became the German managing editor. There was an Advisory Board consisting of accomplished colleagues in the field who supported the journal's objectives and could act as referees for the manuscripts submitted. In 1967, Wing [1] became Editorin-Chief, and R.S. Fleck (New Haven) became the English managing editor.

Among the 26 original articles included in Volume 1 (1966-1967), some particularly stand out: Mechanic's study of illness behaviour [2], Strotzka's socio-epidemiological field study of a rural Austrian town [3], and Rutter and Brown's seminal development of an instrument for measuring relationships in patients' families (expressed emotion), which is still driving research in psychosis and other disorders [4]. The Journal's contents were extended to other fields of social-psychiatric and epidemiological research ranging from the stigma associated with mental illness [5] to the evaluation of US community mentalhealth programmes $[6,7]$, transnational comparisons based on case-register data [8], and the rehabilitation of chronically mentally ill people in England [9].

Key articles in subsequent volumes added to the Journal's reputation. Examples include the replication (with an improved methodology) by Levy and Rowitz [10] of Faris and Dunham's [11] epochal urban-ecological study in Chicago, and Ödegård's [12] case-register analysis of time trends of hospitalisation for psychoses from Norway in 1926-1965.

As the Journal's reputation grew, so did the chief editor's workload. Wing was followed in this role by Fleck, in 1971 and by Norman Kreitman ${ }^{1}$ (Edinburgh) in 1974. In 1976, Häfner relinquished the German editorship to Brian Cooper, who had moved from the Institute of Psychiatry in London to take up a post in Mannheim.

\section{Consolidation}

The founding period was clearly over. The objectives set for the Journal at the beginning had been achieved. It has since published a remarkable array of results that later turned out to represent milestones in the history of the discipline.

The journal has always had an international remit, and this continues: in 2012 articles were submitted from 36 different countries, and accepted from 26 . There were 73 submissions from the United States, compared with 50 from the UK, and 26 from the Netherlands. There were also 22 from China and 20 each from Australia and Canada.

Initially the journal was published four times a year. This increased to 6 issues (1989), to 8 issues (1997), and finally from 1998, to 12 issues. Each issue is now up to 180 pages long. This is one measure of success: the journal was intended to encourage the expansion of social and epidemiological research in psychiatry, and, if its sheer volume is anything to go by, the intervention has been very effective indeed. However, the increasing size of the journal seems to have been accompanied by a corresponding increase in the quality of papers. The combination of volume and quality is made possible because we now receive around 600 articles submitted each year. These changes are a gratifying reflection of the fact that social and psychological aspects of psychiatric disorders have undoubtedly moved to centre stage in the past decade.

Bebbington has occupied the chief editor post since 1993, but is handing over at the beginning of 2013 to $\mathrm{Dr}$ Craig Morgan, one of the most distinguished of his generation of social psychiatric epidemiologists, and someone

\footnotetext{
1 The only chief editor of SPPE to have his poems included in the Edinburgh Book of Twentieth Century Scottish Poetry.
} 
with exactly the right credentials for the role. We leave the journal in good fettle and in good hands.

\section{Heinz Häfner and Paul Bebbington}

A note from the new chief editor

To read the notes from Professor Bebbington (chief editor since 1993, and English language editor before that since 1986) and Professor Häfner (as founding editor) is to be reminded how much of a privilege and responsibility it is to be offered the opportunity to edit Social Psychiatry and Psychiatric Epidemiology. Even such a (relatively) short time ago as 1998, when I started my research as a naive and enthusiastic $\mathrm{PhD}$ student, the relevance and importance of social and psychological aspects of mental disorder were contested, at least in my own primary area of interest, psychosis. I vividly remember a colleague (whose anonymity I will respect) returning from the major European biennial conference on schizophrenia research at the time with the admonition ringing in her ears that the study of social factors in relation to the onset of psychosis should be abandoned. How things have changed! As Professors Bebbington and Häfner comment, the study of social and psychological aspects of mental disorder is now part of the mainstream.

We owe a tremendous debt of thanks to Professor Bebbington for successfully steering SPPE through a period of expansion and for cementing the journal as a significant forum for the dissemination of research on all aspects of psychiatric epidemiology. (Professor Bebbington also examined my $\mathrm{PhD}$ thesis and, having lived to tell the tale, I am grateful to him on more than one count!)

Paradoxically, one reason why it has become clear (if it was not already) that social psychiatry is of central importance to understanding mental disorder is because of research on genetics and neurobiology. It is now abundantly evident that the previously assumed polarities of the biological and social are meaningless. We are social beings. The world around us shapes our biology, just as our biology shapes the world around us. In looking forward, I am particularly keen to encourage submission of papers reporting research at the interface of the social, psychological and biological.

SPPE has always been international and, as such, has run against the grain. The overwhelming majority of research on mental disorder originates in high income countries. This distorts our understanding of mental disorder and of appropriate responses and service provision. One remarkable and welcome change in recent years is the growth of the movement for global mental health. This movement acknowledges the enormous worldwide burden of mental disorder and, some dissenting voices notwithstanding, is surely a positive development. In keeping with the international perspective of SPPE, I very much hope that SPPE continues to be seen as an important focal point for what should be an exponential increase in research outputs from low and middle income countries over the coming years.

Inevitably, a new editor will bring new ideas. In recognising the achievements of Professor Bebbington and other previous editors, I appreciate the need for continuity. I very much look forward, for example, to working with the current editors whose ongoing contributions are central to SPPE's future. Change and renewal are equally important and in this vein I will seek to expand the journal's advisory board. As part of the above goals of increasing submissions of papers on the interface between the social, psychological and biological and on global mental health, a new editor for reviews, Ulrich Reininghaus, will commission a series of state-of-the-art reviews of research on key topics. Synthesis of findings is a crucial element of science.

By building on the foundations built by Professor Bebbington and previous editors I will work to ensure the journal remains a primary outlet for research on social psychiatry and psychiatric epidemiology.

\section{Craig Morgan \\ Editor-in-Chief}

\section{References}

1. Bebbington P (2011) John Wing and the perils of nosolatry. Social Psychiatry 46:443-446

2. Mechanic D (1966) Response factors in illness: the study of illness behaviour. Social Psychiatry 1:11-20

3. Rutter M, Brown GW (1966) The reliability and validity of measures of family life and relationships in families containing a psychiatric patient. Social Psychiatry 1:38-53

4. Strotzka H, Leitner I, Czerwenka-Wenkstetten G, Graupe SR (1966) Sozialpsychiatrische Feldstudie über eine ländliche Allgemeinpraxis. Social Psychiatry 1:83-87

5. Jaeckel M, Wieser S (1967) Studien zur 'unsichtbaren Schranke' bei psychisch Kranken. Social Psychiatry 2:100-106

6. Marcus MG, Edelson M (1967) Priorities in community mental health programs: a theoretical formulation. Social Psychiatry 2:66-71

7. Ozarin LD, Levenson AI (1967) The community mental health centers program in the U.S.: a new system of mental health care. Social Psychiatry 2:145-149

8. Wing L, Wing JK, Hailey A, Bahn AK (1967) The use of psychiatric services in three urban areas: an international case register study. Social Psychiatry 2:158-167

9. Goldberg D (1967) Rehabilitation of the chronically mentally ill in England. Social Psychiatry 2:1-13

10. Levy L, Rowitz L (1970) The spatial distribution of treated mental disorders in Chicago. Social Psychiatry 5:1-11

11. Faris REL, Dunham HW (1939) Mental disease in urban areas. University of Chicago Press, Chicago

12. Ödegård Ö (1971) Hospitalized psychoses in Norway: time trends 1926-1965. Social Psychiatry 6:53-58 